Кілт сөздер: ұялы байланыс, трафик, абонент, Интернет, мобильді станция, таймфрейм, SMS хабарлама, интернет-браузинг, сессия, кідіріс уақыты.

\title{
Orazakova A.N.
}

Scientific superviser: Bakhtiyarova Ye.A.

On the improvement and evaluation of cellular communication services

Abstract. The article presents the basic methods for assessing the quality of cellular services. The main requirements and characteristics of testing the quality of the service provided by mobile operators are given, and the direct test procedure for each type of service is described in detail.

Keywords: cellular communication, traffic, subscriber, Internet, mobile station, timeframe, SMS message, Internet-browsing, session, delay time.

\section{Сведения об авторах:}

Бахтиярова Елена Ажибековна, к.т.н., ассистент-профессор, заведующая кафедрой «Радиотехники, электроники и телекоммуникаций» Международного университета информационных технологий.

Оразакова Айбала Нурахметовна, магистрант кафедры «Радиотехники, электроники и телекоммуникаций» Международного университета информационных технологий.

УДК 621.396

\author{
Кожахметова Б.А. ${ }^{1}$, Кулакаева А.Е. ${ }^{2}$, Онгенбаева Ж.Ж. ${ }^{3}$ \\ 1,3Международный университет информационных технологий, \\ Алматы, Казахстан \\ ${ }^{2}$ Satbayev University, Алматы, Казахстан \\ Научный руководитель: Айтмагамбетов А.З.
}

\section{ВОПРОСЫ ИСПОЛЬЗОВАНИЯ АФАР В СИСТЕМАХ СПУТНИКОВОГО МОНИТОРИНГА}

\begin{abstract}
Аннотация. В статье рассматриваются вопросы использования перспективных на сегодняшний день антенн АФАР в системах спутникового мониторинга. В работе приводится обобщенная структурная схема антенны, а также предъявляются требования к антенной системе для реализации системы спутникового мониторинга за источниками излучения.
\end{abstract}

Ключевые слова: АФАР, спутниковый мониторинг, электрическое сканирование, фазовращзатель, источник радиочзлучения.

\section{Введение}

В современном мире, в условиях развития новых радио-технологий, значительно возрастает число радиоэлектронных средств (РЭС), использующих радиочастотный спектр (РЧС). Для осуществления контроля излучений каждого источника радиоизлучения (ИРИ) и определения его местоположения в пространстве, необходимо использовать оборудование с антеннами, которые позволили бы: произвести обзор окружающего пространства, определить направление на ИРИ, исследовать распределение ИРИ в окружающем пространстве. Перечисленным требованиям при современном уровне развития антенной техники наилучшим образом удовлетворяют фазированные антенные решетки (ФАР). Среди возможных конструктивных решений ФАР следует выделить активные фазированные антенные решетки 
(АФАР). В данной антенной системе имеется множество излучающих элементов, которые позволяют повысить энергетический потенциал антенной системы, а также получить узкую диаграмму направленности по сравнению с единичным излучателем. Преимуществом АФАР является то, что к каждому излучателю антенной решетки подключается активный элемент в виде генератора, усилителя мощности или преобразователя частоты [1]. Обобщённая схема АФАР приведена на рисунке 1 и содержит в себе:

- системы формирования и управления положением луча антенны, которая создает необходимое распределение амплитуд и фаз сигнала в излучателях решетки. Эта система содержит набор усилителей мощности, набор фазовращателей, а также набор согласующих цепей;

- решетки излучателей, которая образует апертуру антенны и состоит из набора одинаковых слабонаправленных излучателей, расположенных обычно в узлах прямоугольный или косоугольной сетки;

- делителя мощности, обеспечивающая распределение сигнала от общего возбудителя по всем каналам АФАР, характеризуемая рабочей частотой, КПД, выходной мощностью, стабильностью характеристик и др.

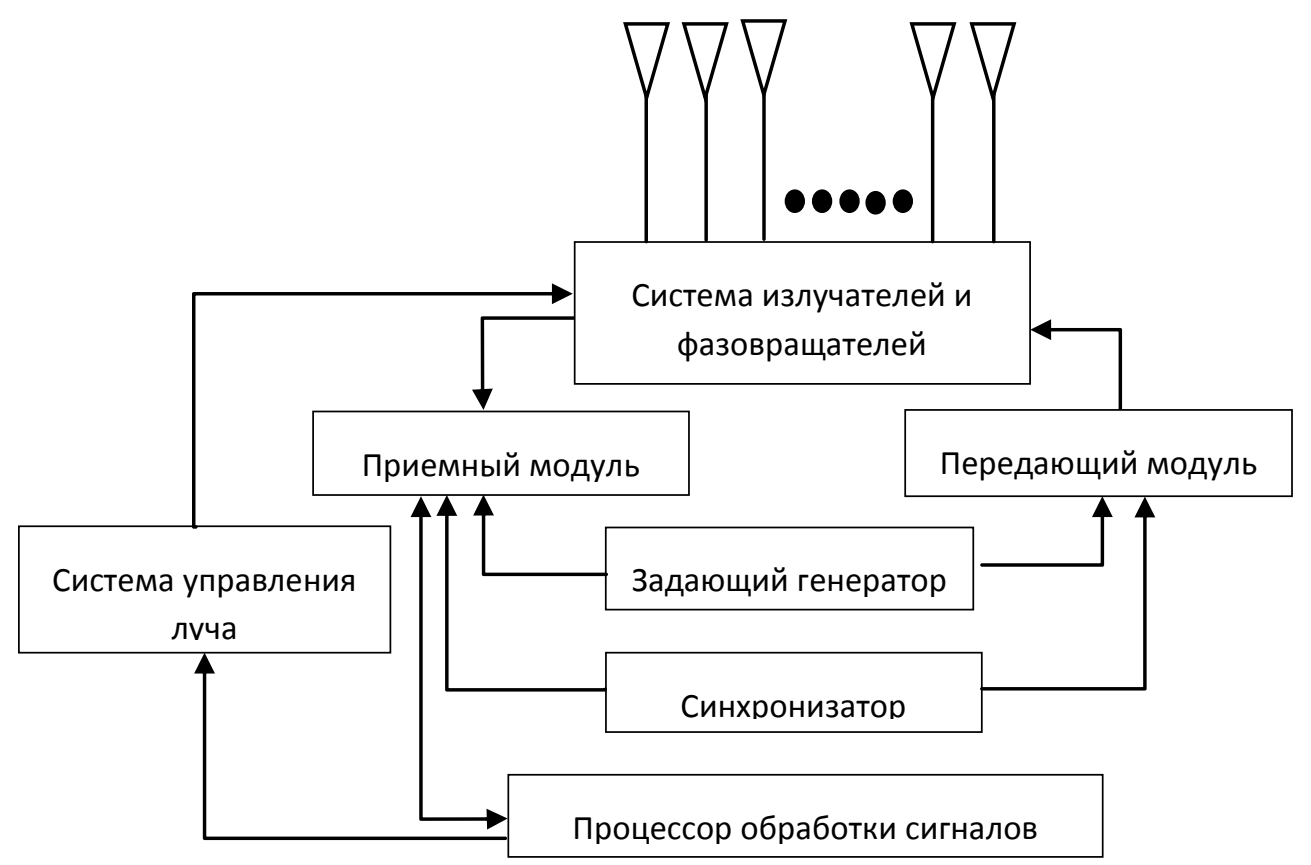

Рисунок 1 - Обобщённая схема АФАР

\section{Применение АФАР}

Антенные системы на базе АФАР на сегодняшний день являются перспективными, и находят применение в таких радиотехнических системах, как: радиолокация и радионавигация, мобильная связь.

В работах [2,3] рассматривается возможность использования в качестве спутникового мониторинга одного низкоорбитального малого космического аппарата (МКА), который позволит проводить радиоконтроль наземных ИРИ, в том числе и определять координаты местоположения ИРИ. Для реализации такой системы предлагается использовать на борту антенны типа АФАР. Однако для достижения данной цели предъявляется ряд требований:

- возможность быстрого (безынерционного) обзора пространства за счет качания лучей антенн электрическими методами (электрическое сканирование);

- узкие лучи в одном направлении для повышения точности определения угловых координат ИРИ и широкие - в ортогональном направлении;

International Journal of Information and Communication Technologies, Vol.1, Issue 1, March, 2020 
- увеличение уровней принимаемой мощности за счет размещения в каналах решетки усилителей высокочастотной энергии;

- особенно важно то, что расположение элементов в АФАР должно обеспечить пространственный сектор сканирования по сферической поверхности Земли.

Совместная обработка сигналов, принятых отдельными элементами антенных решеток, позволит получить более полную и точную информацию об излучении ИРИ.

Система спутникового радиомониторинга ИРИ позволяет охватывать большие территории земной поверхности (рис.2). МКА, находящиеся в области радиомониторинга, регистрирует ИРИ и пересылает данные о координатах местоположения ИРИ (широта и долгота) в наземный центр обработки данных (ЦОД) [5].

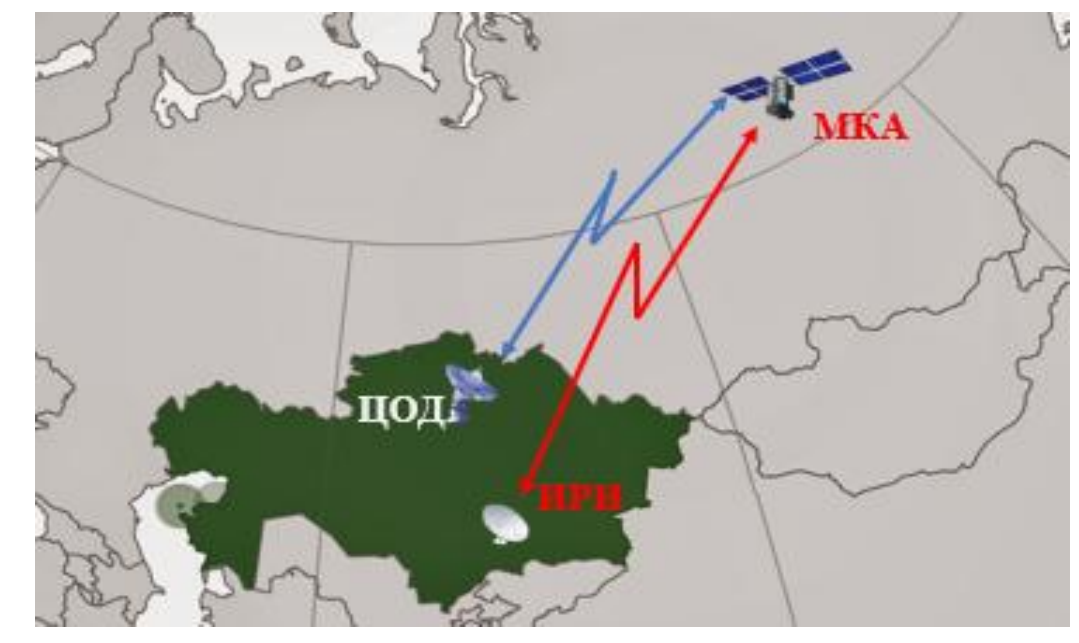

Рисунок 2 - Спутниковая система радиомониторинга ИРИ на базе одного МКА

Заключение. Таким образом, антенные системы на базе АФАР на сегодняшний день обладают большими преимуществами и получают широкое распространение в радиотехнических системах благодаря возможности быстрого сканирования лучами зон покрытия. Необходимо проведение исследований конструкций АФАР с целью уменьшения габаритов и веса АФАР, снижения стоимости и сложности проектирования при большом количестве элементов антенн.

\section{ЛИТЕРАТУРА}

1. Устройства СВЧ и антенны. Проектирование фазированных антенных решеток: Учеб. пособие для вузов / Под редакцией Д.И. Воскресенского. Изд. 4-е, перераб. и доп. - М: Радиотехника, 2012. - 744 с.

2. Aitmagambetov A.Z., Butuzov Yu.A., Kulakayeva A.E. Mathematical models for determining the location of radio emission sources in radio monitoring systems on the basis on low-orbit satellites. T-Comm. 2016.Vol. 10.No.1, pp. 73-76.

3. Айтмагамбетов А.З., Бутузов Ю.А., Кулакаева А.Е., Сатеров Н.М. Вопросы анализа сигналов и опознавания передатчиков при спутниковом радиомониторинге. - Вестник КазАТК. - Алматы, 2015.- №5-6 (95). - С. 47-51.

4. Вендик О.Г., Парнес М.Д. Антенны с электрическим сканированием (введение в теорию) / Под ред. Л.Д Бахраха. - 2001.

5. Вопросы применения активных фазированных антенных решеток в радиотехнических системах. Кожахметова Б.А., Камал Р.Ж., Койшыбай С.С. Современные технологии в науке и образовании - СТНО-2019: сб. тр. II междунар. науч.-техн. форума: в 10 т. Т.1./ 
под общ. ред. О.В. Миловзорова. - Рязань: Рязан. гос.радиотехн. ун-т, 2019; Рязань. - 206 с., - C.47-50.

Кожахметова Б.А., Кулакаева А.Е., Онгенбаева Ж.Ж.

Ғылыми жетекші: Айтмагамбетов А.3.

Спутниктік мониторинг жүйелерінде БФАТ пайдалану мәселелері

Андатпа. Мақалада бүгінгі күні перспективалы БФАТ антенналарын спутниктік мониторинг жүйелерінде пайдалану мәселелері қарастырылады. Жұмыста антеннаның жалпыланған құрылымдық схемасы келтіріледі, сондай-ақ сәуле шығару көздеріне спутниктік мониторинг жүйесін іске асыру үшін антенналық жүйеге талаптар қойылады.

Кілт сөздер: БФАТ, спутник мониторингі, электр сканерлеу, фаза айналдырғыш, радиосәулелену көзі

\section{Kozhakhmetova B. A., Kulakayeva A. E., Ongenbaeva Zh.Zh. Scientific superviser: Aitmagambetov A.Z. \\ The use of APAA in the systems of satellite monitoring}

Abstract. The article deals with the use of currently promising APAA antennas in satellite monitoring systems. The paper provides a generalized structural diagram of the antenna, as well as requirements for the antenna system for implementing a satellite monitoring system for radiation sources. source.

Key words: APAA, satellite monitoring, electric scanning, phase shifter, radio emission

Сведения об авторах:

Кожахметова Багдат Абдурашидовна - лектор, магистр кафедры «Радиотехника, электроника и телекоммуникаций» Международного университета информационных технологий.

Кулакаева Айгуль Ергалиевна - PhD докторант второго года обучения Satbayev University.

Онгенбаева Жадыра Жумабековна - сениор-лектор, магистр кафедры «Радиотехника, электроника и телекоммуникаций» Международного университета информационных технологий.

Айтмагамбетов Алтай Зуфарович, профессор кафедры «Радиотехника, электроника и телекоммуникации» Международного университета информационных технологий.

International Journal of Information and Communication Technologies, Vol.1, Issue 1, March, 2020 